\title{
Review on Stationary CPT Technologies and Coil Designs for EVs
}

\author{
Junlong Duan* and Weiji Wang \\ Department of Engineering and Design, University of Sussex, United Kingdom
}

Submitted: January 14, 2020; Published: January 31, 2020

*Corresponding author: Junlong Duan, Department of Engineering and Design, University of Sussex, Brighton BN1 9QT, United Kingdom

\begin{abstract}
In the recent decade, the driving range of pure EVs with zero emission target has become a popular topic as the massive battery requirement for longer distance travels means higher vehicle cost and longer time of recharging periods. Stationary CPT charging solutions could be an alternative to reduce EVs weight, size and energy storage unit costs. Fortunately, with progressive success of low-power CPT charging applications proposed to be commercially produced in the past decade, hundreds of kilowatts level high-power CPT charging techniques for EVs are more and more expected to be an optimally suitable solution for recharging EV batteries, providing higher propulsion and delivering continuously longer driving range in the next generations of the EVs. The idea of deploying inductive coupling for EVs has acquired a lot of attentions in the last decade due to the contributions and advancements of power electronics, switching power supply, semiconductors, microprocessors, electrochemistry, material sciences, control technologies, electromagnetics and so on, despite many challenges to be addressed including EV manufacturing integration with CPT system under the chassis, infrastructure difficulties, system maintenance on both vehicle and transmitting ground sides, actual CPT performance with real-time coupling on real-world road. In order to ensure the realization and enhance the sustainability in transportation sector with the emerging CPT ideas, currently the stationary CPT charging solutions based on inductive power transfer (IPT) have been developed from laboratory level as a first step to the practical tests of commercial realizations. In a few industrial fields nowadays, some of the proposed CPT technologies with specific coupler coil designs have been expected for real-world applications. This article presents a state of the art of the CPT technologies and focuses on reviewing current coil designs for high-power contactless energy transfer for EVs in the literature. .
\end{abstract}

Keywords: Contactless power transfer (CPT); Wireless power transmitting (WPT); Inductive power transfer (IPT); Coupler; Coil designs; Ferromagnetic materials; Ferrite cores; Charging efficiency; Power transfer ratings

\section{Introduction}

The mainly significant performance parameters and objectives of a satisfied CPT system are power transfer rating level, maximum charging distance, system maximum efficiency, charging tolerance to misalignments, system size and weight. The power level can refer to how long one full battery recharge would take for a full driving range of EV. The maximum charging distance determines the vehicle chassis structure for achieving contactless charging. The system efficiency is the overall comprehensive parameter of the entire system, which illustrates how electrically efficiently the CPT phenomenon operates from AC power supply end to DC battery end for the EV. Charging tolerance could reveal how the horizontal and longitudinal misalignments caused by EV drivers' parking habits impact the actual coupling charging and power delivered between primary coil and secondary coil, which also indicates how the flexibility and advantages of CPT systems are when compared with conventional plug-in charging methods. The stationary CPT technologies could comprise loosely inductive coupling and electromagnetic resonant coupling depending upon different operating frequency range levels and capacitive compensation adoptions, which are both based on inductive coupling phenomenon and most of the time are collectively called inductive power transfer (IPT) in the literature.

\section{Principles of Stationary CPT systems}

For the technical background and fundamental principles of contactless power transfer systems, Figure 1 and Figure 2 illustrate the typical systematic diagram and basics of IPT based stationary CPT systems. When the IPT charging system is activated by the signal from EVs reaching over the particular charging platform, the power supply under pavement will provide $230 \mathrm{~V} \mathrm{AC} \mathrm{mains}$ to a transformer converter which could convert and rectify the high voltage power to required range of DC voltage. Then, a high frequency (HF) inverter converts the low frequency DC power to HF $\mathrm{AC}$ power. Before being sent to transmitting pad, the HF AC power is supposed to go through the compensation module [1] which is considered to optimize the transformer loss factor. Contactless 
power transfer coupler transmits the power to the vehicle side via effects of magnetic flux linkage namely inductive phenomenon. After receiving the induced $\mathrm{AC}$ power, the compensation circuit and rectifier/AC-DC converter would operate on the power then the DC to DC converter of direct conversion method converts the energy to a required voltage with appropriate low frequencies for battery energy storage in the end of the whole CPT system. At a basic level of a real-world CPT system, a power supply requirement before the coupling module as depicted in Figure 2 is supposed to include an input rectifier and filtering section, an $\mathrm{H}$ bridge inverter section and current controller if necessary.

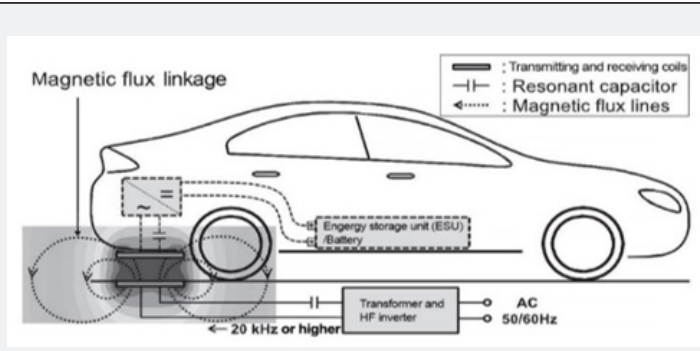

Figure 1: A loosely inductive coupling and magnetic flux linkage-based CPT system for stationary EV charging.

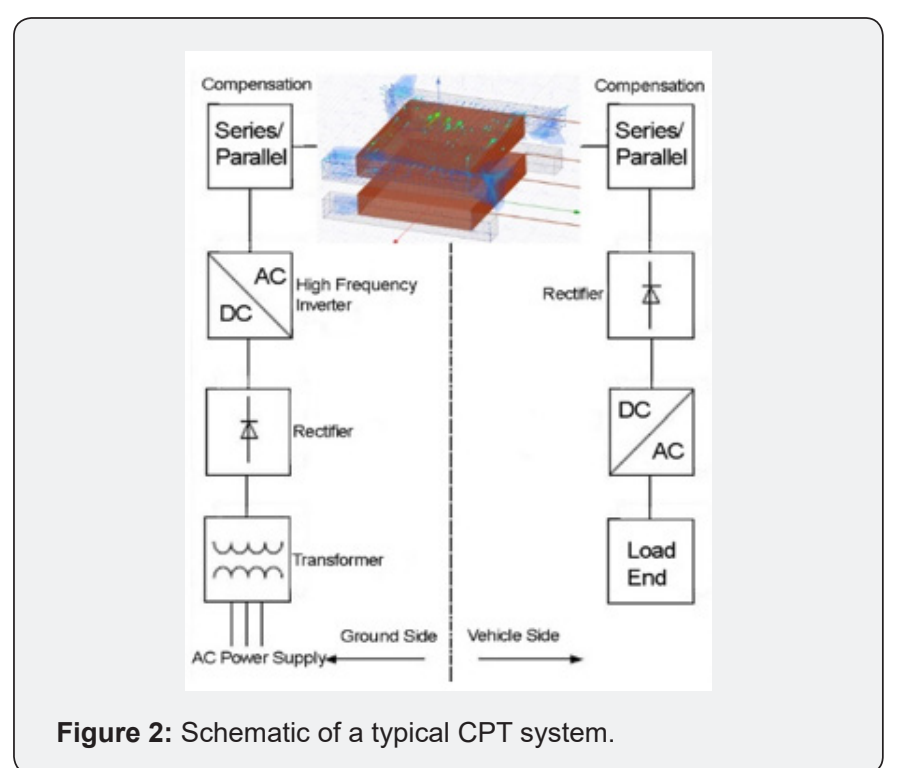

\section{History}

In 1887, Nikola Tesla invented induction machine that converts electrical power to mechanical power from a stator to a rotor, which inspired Tesla again to come up with the idea of wirelessly transmitting energy via large air gaps based on the principle of electromagnetic induction machine that was just technically and commercially proved by himself. In 1901, the concept of wireless power transmitting (WPT) was firstly proposed and was believed by Nikola Tesla that it can be used to transfer electricity even far from America to Europe with an electromagnetics based giant tower named Wardenclyffe tower in USA, which was terminated by US government in 1917 and proved that the actual coupling distance is a huge obstacle to WPT efficiency and effectiveness. Since then, some experiments were implemented in order to wirelessly transfer power to a moving train with coupled energy but still went unsuccessful, which on the other hand proved that only low-power signal could be transmitted over large distances such as radio frequency (RF) signals, microwaves, etc. A conclusion was made at that time that electrical power wirelessly transmitted is practically impossible from a power point of view throughout the rest of 19th century [2]. Whilst on the 'signals' side, the sciences over communication systems, non-contacted current sensors and inductive antennas had been significantly developed based on Maxwell equations, laws of Ampere's and Faraday's and attempts of Nikola Tesla's WPT.

With the attempts of powering EVs inductively since 1970s, stationary CPT topics were re-proposed at the same time. In 1986, Kelly and Owens [3] designed a wireless power transfer method for a low-power level aircraft entertainment system with $38 \mathrm{kHz}$ currents going through wires under the carpet successfully coupling and delivering $8 \mathrm{~W}$ power for each passenger entertainment platform despite very low transfer efficiency. In 1990, this wireless aircraft entertainment system powering innovation named 'regulator for inductively coupled power distribution system' was enhanced with a voltage controller and was patented by Turner and Roth for Boeing aircrafts in the US [4].

In the beginning of 1990s, as academic pioneers, Boys and Green developed a systematic stationary CPT technology and patented it in the US [5] with the first definitional names in this area: inductive power transfer (IPT) or inductively coupled power transmission (ICPT) system, which includes an elongate inductor, parallel capacitive compensation, paralleled pickup coils, decoupling and voltage controllers [6]. This complete IPT system was modified and improved with enhanced control circuits by Boys, Covic and Green in 2000, which resulted in an output of up to $600 \mathrm{~W}$ with a maximum voltage of $600 \mathrm{~V}$ at $10 \mathrm{kHz}$ by the system power supply [7] and, thereby from the power point of view, it was apparently unable to sufficiently power tens of kilowatts level EVs or to accomplish hundreds of kilowatts level required fast highpower battery charging cycles of EVs.

Since 2000, the performances of different stationary CPT approaches were significantly improved most of the cases in lab researches rather than industrial level applications. In 2007, MIT WiTricity project group made a demonstration and claimed that their wireless power transmission system can lighten a $60-\mathrm{W}$ bulb over 1 and 2 meters at $9.9 \mathrm{MHz}$ with a transfer efficiency of between $30 \%$ and $90 \%$. This demonstration itself was convincing but the measured results were unavoidably doubtful when analysed according to previous studies and experiments over the past decades in the literature. Nevertheless, the development of stationary CPT technologies has been facilitated dramatically by 
the academic interests and the commercial market requirement of EVs towards pursuits of zero emission transportation era in the 21st century.

\section{Current status}

Among the various previous studies and reports in the literature, it can be noticed that numerous subtopics have been covered and many breakthroughs have been made towards the CPT system performance optimization and the commercially productive realization for EVs. A variety of applications based on inductive power transfer principle have diversified and the actual technical challenges have been becoming more noticeable at the same time, especially for the stationary and dynamic high power required contactless charging for real-world EVs. Nonetheless, the inductive coupling-based CPT technologies and the derived techniques are promising. This section briefly reviews the developments of stationary charging for EVs over the past decade and presents the state of the art of stationary CPT method.

More recently within the past decade, a series of research institutes, university research groups and industrial manufacturers have been playing pioneer roles in this field and making new knowledge contributions from different aspects.

Oak Ridge National Laboratory (ORNL), as a bullet research institute sponsored by the US Department of Energy in the CPT area, has carried out some practical experiments empirically resulting in some analyses and conclusive methods in the national research centre lab in Tennessee. ORNL focuses on grid-tied high frequency power inverter, grid side regulation converter, control system and loosely coupled coil design. Based on the new ultrathin silicon IGBT technology, an experimental power inverter and a grid-tied power converter were designed and tested by ORNL in 2012 [8], which aims to minimize the mass and size of the coil, rectifier, filtering, wires, and other components mounted on the secondary side of vehicle chassis [9].

A 5-kW output inductive stationary CPT system was designed by a group of the Utah State University, in which an external 37-W power required FPGA sensors/controller was added to the CPT system for the dual-side control. Circular coils and LCL converter were used in this system. Practical experiments in this study were used to validate the effectiveness of the proposed schematic, by which the researchers claimed that the system can maintain a very optimistic efficiency from the grid side to the load in spite of too many ideally assumed conditions that were made in the derivative analyses and post-data processing [10]. Nonetheless, a dual-side control method in this report was proposed to the inductive coupling system as an innovative way.

A researcher of the University of British Columbia deployed a set of magnetic gears as transmitting and receiving magnets, an electric motor on the ground side and a generator on a car chassis to realize a wireless power transmitting, which is implemented and accomplished via coupling magnetic gears and driving the generator on the car to power the vehicle motor. It was claimed that this system could reach a maximum transmission part efficiency of $81 \%$ with a transferred power of $1.6 \mathrm{~kW}$ at a very low frequency of $150 \mathrm{~Hz}$ [11]. Regarding the feasibility and realization by gear coupling and re-generating electricity in a real-world EV charging application, the proposed system seems to be doubtful in this study as the additional process of driving the secondary generator via the magnetic field stored energy for inductively producing the electricity itself would unavoidably introduce more power losses eventually contributing to a further reduction of overall system efficiency ratio.

Two researchers of the Setsunan university in Japan conducted investigations on several different coil dimensions, in which it was found that three-dimensional horn-shaped antennas as transmitting and receiving coils could lead to higher power transfer efficiency than patch and array antennas whilst the patch antennas in a nature of planar could be more practical and suitable for EVs chassis CPT system installation. Thus, the size and operation performance are to be a trade-off when considering the entire stationary CPT system from design to actual fabrication onto EVs. In this study [12] of the University of Setsunan, the system operating frequency is between $1.2 \mathrm{Ghz}$ and $2.45 \mathrm{GHz}$, which is in a range of $\mathrm{HF}$. Besides, it is claimed that the array antennas perform with lower transmission loss than patch antennas at $2.45 \mathrm{GHz}$ and with a transmission efficiency of over $20 \%$ despite of unknown actual power transferred through the entire system.

A team of Tokyo University contributed numbers of reports to the field of CPT technologies in the past ten years. Based on the method conceptualized and named with electromagnetic resonant coupling by MIT WiTricity in 2007, the research group of Tokyo University started studying the feasibility and technical performance of this method with theoretical and practical depth since 2009. Different from the previous inductive power transfer (IPT) methods and concepts, the proposed electromagnetic resonant coupling technology emphasizes on impedance matching [13] in order for the whole system to approximate to magnetic resonance, by which predictably the energy transfer efficiency of the CPT system could be optimized and theoretically the actual power rating to the load could be very satisfactory. This group of researchers considered the CPT technology as small-sized helical antenna transmission topics and pure electrical equivalence problems [14,15] which led to a convenience of investigating the system with the antenna scattering parameter (S-parameter) analysis and the direct experimental methods of using a vector network analyser (VNA) [16] to measure the outputs at a usable frequency of the industrial, scientific and medical (ISM) band-13.56 $\mathrm{MHz}$ [17]. Significantly, the impedance matching theory contributes to the theoretical structure construction of CPT technologies, especially for the magnetic resonance accomplishment in this case. Whilst, the over-idealized impedance matching circuits used in this case neglects the non-linear magnetic circuit part in 
the coupling module, which determines a lot regarding how the actual electromagnetic flux distribution contributes to the realtime coupling phenomenon over the air or core based distance with non-linear magnetic characteristics in nature such as B-H curves and hysteresis effects in the electromagnetic field. Thus, the absolutely equivalent circuit method in the case of this research group may be not sufficiently appropriate and suitable for a CPT system scenario. Besides, working at megahertz level operating frequency and considering the system as a pure antenna problem especially with traditional scattering parameter analysis may be not proper as firstly the real-world CPT systems are not milliwatts level 'signal transmission' topics from power point of view, and secondly the VNA measurement with a two-port network S-parameter method may not be adequately applicable any more when it comes to kilowatts level electrical power issues despite of resonance status. Nevertheless, the University of Tokyo team did make contributions towards the knowledge gaps at that time in the last years of 2000s. With the same methodology, a battery hybrid energy storage system was also studied by this research group, by which it is claimed that both the transmission side power control configuration and the receiving antenna side controller were designed to achieve satisfactory power charging without communication units between transmitting and receiving antennas [18]. However, the Tokyo University research team turned to study the CPT systems in a loosely coupled frequency range in the order of kilohertz [19] rather than megahertz anymore since about 2014. More practically in laboratory and realistically in applications this time, the researchers mainly investigated the circuit topologies, transmission coil types, control methods and capacitor compensations in depth, pointing out that the effectiveness of magnetic resonance to the wireless power transfer coupling purpose and proving that the new methodology contributes more to the system efficiency and power transfer rating issues [20] with results of $40-90 \%$ and $60 \mathrm{~W}$, respectively.

On the other side in industry, several technology driven companies and manufacturers havealso been making contributions to the field of emerging wireless power transfer technologies for stationary charging from multiple levels and aspects over the past twenty years, such as WiTricity Corporation, Bombardier, HEVO Power, Qualcomm Group, Conductix-Wampfler etc.

As mentioned before in the last section, WiTricity as a corporation was founded by a group of MIT researchers to investigate and invent wireless energy transmission terminals for commercial purposes since the first demonstration in 2006. With the proposed resonance coupling method, WiTricity team designed a CPT system with tuned coils to wirelessly transfer power which was claimed with $60 \mathrm{~W}$ to $3.3 \mathrm{~kW}$ over one meter at $145-\mathrm{kHz}$ operating frequency [21-24]. Afterwards in 2011, some other researchers in East Asia carried out resonant coupling simulations based on WiTricity designs and studies the position tolerance of the method, by which it was claimed that the simulated
WiTricity model showed a maximum performance at $2.34 \mathrm{MHz}$ with a coil distance of $50 \mathrm{~mm}$ [25]. However, in this report a real power rating and effectively convincing system efficiency were not derived and discussed in detail although the peak values of output voltage magnitudes corresponding to various coil distances and frequencies were recorded and compared.

Bombardier Transportation company, a leading technology and solution supplier in Germany, tested their wireless static charging system called PRIMOVE for buses in 2013. As part of the pure electric public buses, the PRIMOVE system has been integrated with improved EV system via this project. Bombardier designed their own control unit named 'vehicle detection and segment control' (VDSC) and interface called 'supervisory control and data acquisition' (SCADA) subsystems at industrial levels [26], which seems to be feasible and successful in the real-world application despite of insufficient technical reports or data released and published yet.

HEVO Power is another technology provider in the US which aims to innovate a wireless charging system for public transportations. This company proposed a stationary system requiring a fixed operating frequency of $85 \mathrm{kHz}$ and targeting at transferring up to $10-\mathrm{kW}$ power over an air gap of about $30 \mathrm{~cm}$. It was claimed in 2014 that the receiving side prototype mounted on the vehicle weighs 11 to $23 \mathrm{~kg}$ and that the heating problems on both the vehicle and ground charging sides can be prevented by their parking zone design and mobile phone app monitoring [27]. Qualcomm, a pioneer company dedicated in communication technologies, informatics and lately emerging wireless power transmission, has also been implementing research programs towards an optimal wireless charging equipment for both lowpower electronic devices and high-power charging applications.

Qualcomm Halo is a specific project regarding achieving CPT charging for EVs. Qualcomm aims to realize three options of charging power ratings for future customers in their report in 2013, which are $3.3 \mathrm{~kW}, 6.6 \mathrm{~kW}$ and $20 \mathrm{~kW}$ and targets at very high and stable efficiency rate of over $90 \%$. With IPT method, proposed BiPolar and DD coil designs, Qualcomm claimed that their Halo IPT system used $20-\mathrm{kHz}$ operating frequency in the simulation experiments and trial runs of this prototype would be implemented in East London in 2011. It can be noticed that, from the official reports and research report [28] in collaboration with Auckland University, Qualcomm Halo project is very practically profound and technically convincing with strong simulation supports and mathematically theoretical representations by themselves and other researchers [29]. Besides, the double D method has been patented by Qualcomm years ago from commercial point of view. Conductix-Wampfler, another technology company in CPT research, is very dedicated in investigating inductive power transfer (IPT) techniques and already patented their own IPT trademark in the US. This company focuses on developing IPT system for 
automated guided vehicles (AGV) in warehouse applications with robotics [30,31]. According to their reports until 2018, ConductixWampfler aims to produce the power supply module, charging mat and power pickup with charging manager unit. Technically, the power supply AC voltage can be one-phase $100-240 \mathrm{~V}$ or threephase $380-480 \mathrm{~V}$ at 50 or $60 \mathrm{~Hz}$, the output power and current can be $1.5 \mathrm{~kW}$ and $5 \mathrm{~A}$, respectively. Their power pickup namely receiving coil module with charging manager subsystem aims to inductively receive about $55 \mathrm{~V}$ induced voltage and $10 \mathrm{~A}$ current to send to charge a $24-\mathrm{V}$ DC battery with $12-\mathrm{A}$ and $144-\mathrm{W}$ after the power regulation, DC/DC converter and current monitoring of the charging manager subsystem. The dimensions of power pickup pad and charging mat are H $80.3 \mathrm{~mm}$ x W $222 \mathrm{~mm}$ x D 216 mm and H $7 \mathrm{~mm}$ x W $435 \mathrm{~mm}$ x D $180 \mathrm{~mm}$, respectively. The aim of the charging distance is $10 \mathrm{~mm}$. It can be seen that ConductixWampfler shows not only respectful ambitions but also technical skills in the industrial applications for AGV in warehouse systems.

\section{Proposed designs of coupling coils}

As the most important part of contactless power transfer systems with regards to the overall system outputs and performances, the coupling module design especially the coil geometry design plays a significant role in order for any types of CPT architectures from both the power electronics and electromagnetics perspectives to eventually address the three main objectives: electrical power transfer ratings of the system; efficiencies including overall system efficiency to the load end and coupling part efficiency; CPT air gaps namely charging distances. Therefore, it is very worthwhile proposing, analysing and evaluating various coil designs to comprehensively implement the investigations upon CPT technologies. In this section, the proposed coil designs in the literature until present are to be enumerated and briefly analysed.

\section{Circular coils}

Until present, from the academic studies to the real-world commercial applications, the circular coil designs have become the most common and acceptable approaches for various powerlever devices such as wireless charging pads for smart phones and many other portable electronic products. Also, as for the initial feasibility for high-power level EVs contactless charging, circular coil with its derivative topologies has been focused and developed towards the optimizations and some of them are originally derived from traditional pot cores, according to the reports in the literature [32-34]. Within the current studies and even commercial level applications, most of the circular coil designs are coreless especially for low-power cases [35-37].

As known in transformer theories and applications, the ferromagnetic cores like ferrite cores are deployed to prevent excessive energy loss into surrounding air and materials due to existence of magnetic leakage. And with the fairly tiny air gap design crossing the core structure instead of completely enclosed core loop, the core windings can have minimum disadvantages when effects of proximity occur due to hysteresis loss and eddy current loss. Similarly and theoretically, deploying ferromagnetic cores like ferrite in CPT coil designs is able to constrain magnetic flux lines to expected paths and to shape the actual electromagnetic field in order to enhance the effectiveness of coupling, which consequently improves the wireless energy transfer system performance.

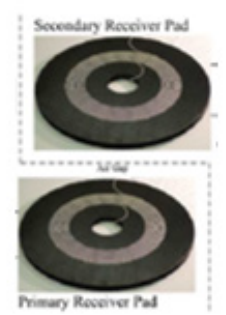

Figure 3. Circular coil design with ferrite pads.

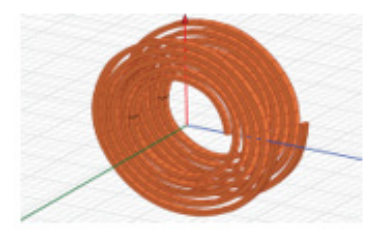

Figure 5. Simplified planar circular coreless coils.

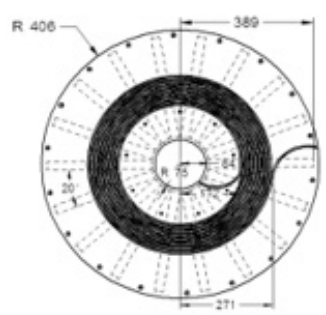

Figure 4. Dimension of a circular coil with ferrite pads.

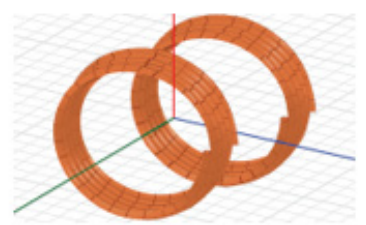

Figure 6. Simplified coreless solenoid coils. 
In most small-scale low-power CPT systems for portable electronic devices like cell phones, wireless charging pads with coreless coils can acquire more popularity due to pursuits of relatively thin and lighter design from real-world customers, certainly under acceptable conditions such as charging power rating and basic efficiency to be at least satisfied by manufacturers' efforts on advanced electronic circuitry and control unit designs. However, high-power CPT applications are more supposed to need cores to assure the satisfactions of the overall system performance [38,39], for instance, the circular coil couplers with solid ferrite pads could form the flux distribution much better. A design of circular coil with ferrite pad is shown in Figures 3 \&4 [10], in which the dimension is in $\mathrm{mm}$. And two coreless circular coil designs are illustrated in Figures $5 \& 6$ for comparisons.
In addition, the derivatives of circular design have also been depicted here in Figures $5 \& 6$ [40]. In this article, the former design could be called a design of simplified planar circular coreless coils and the latter one could be called a design of simplified coreless solenoid coils, with a categorization nomenclature based on the characteristics and natures introduced above. The model in Figure 7 could be named a design of circular ring coreless coils, which illustrates expected magnetic flux lines and distributions in 3D magnetic simulation. It can be seen that with no ferrite pads or cores, the flux lines flow through the coils showing more naturally and smoothly curved paths in air, which can be different from the circular coils with shaping effects by ferromagnetic materials such as ferrite pads used on the external sides.
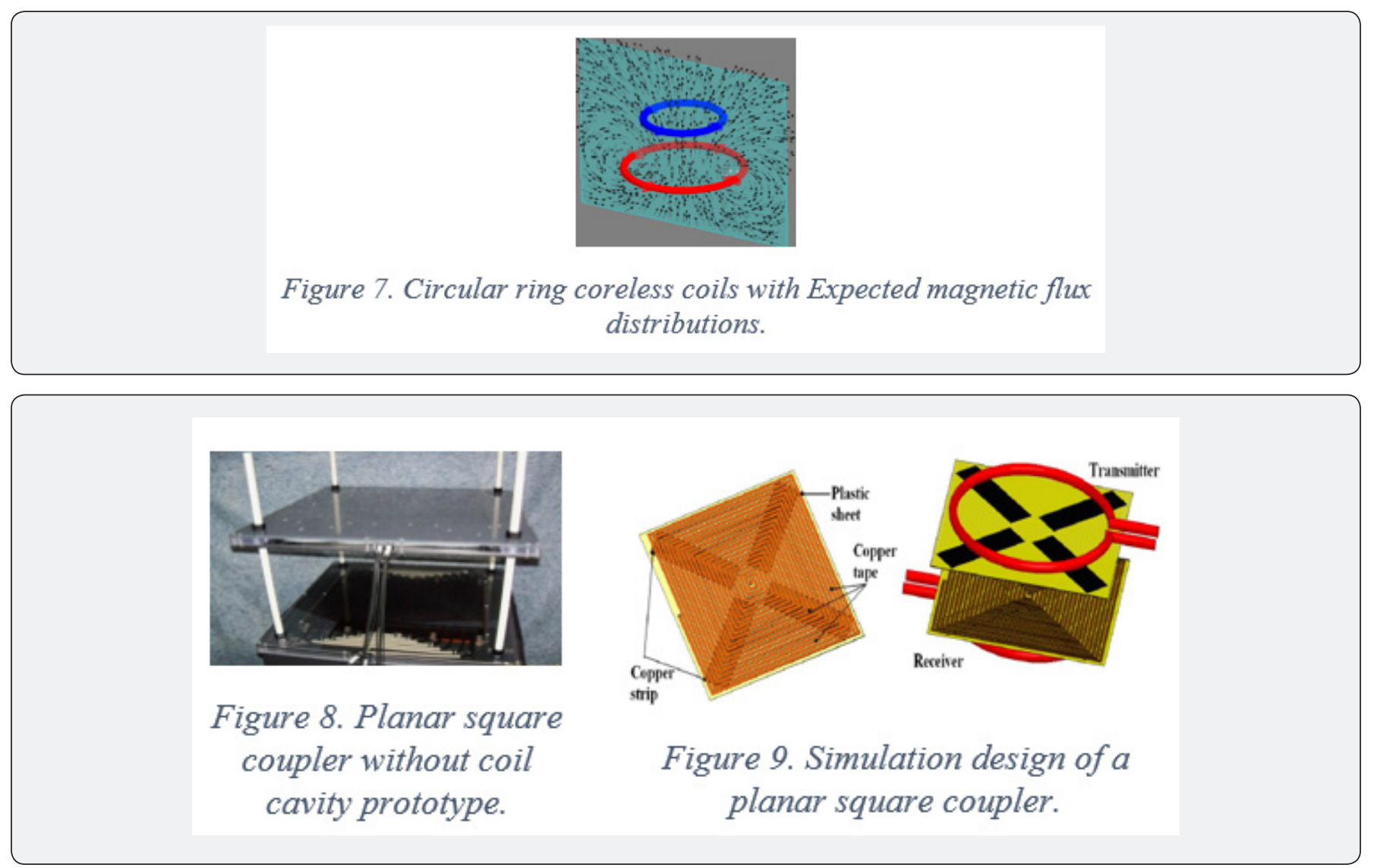

\section{Planar square coils}

Geometrically, square windings can take better advantage of the space under the chassis of vehicles for system installation. Some reports also have already presented the designs regarding square coils and the derivatives and practically tested. The Oak Ridge National Laboratory (ORNL) in the US proposed the detailed designs of their square coupler shown in Figures $8 \& 9[8,9,41]$ for which a category name of 'planar square coil without a cavity' can be applied based on the reviewed designs and categorization nomenclature in this article. The square coils of ORNL are single- layered with multiple circles of windings as illustrated and the winding wires are made of copper. No ferromagnetic materials are used in this design. Considering different magnetic flux lines generated and formed by whether or not a cavity exists in the planar coils, another derivative design can be categorized into 'planar square coils' here. Compared with the planar square coil without a cavity prototype, the model that can be named the 'planar square coil with a cavity' has been presented in [42], which is nearly based on the same dimensional parameters except the empty cavity design existence within the coils as shown in Figures $10 \& 11$. 


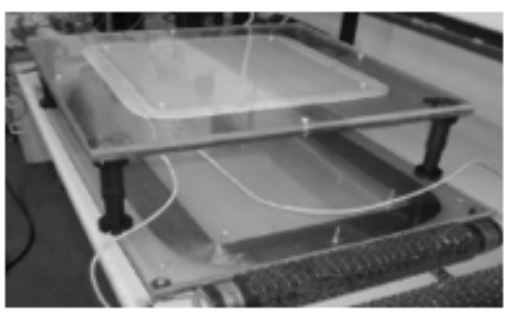

\section{Figure 10. Planar square} coil with cavity.

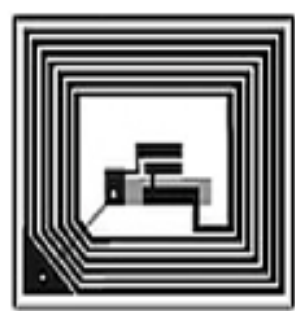

\section{Figure 11. Simplified simulation design of a planar square coil with cavity.}

\section{Solenoidal square coils}

When the installation space under a vehicle chassis is not a major issue, for instance for small-sized automated guided electric vehicles (AGEV) in warehouse rather than on public traffic road, a combination design of solenoid coils and square coils can be proposed, which here is named 'solenoidal square coil' despite a different name in the original report [43]. By a comparison analysis in this article, it can be explained that, the huge dimensional size of this kind of design can take advantage of the intracavity space of the AGEV and theoretically present the optimal performance of both planar square coil and solenoidal coil due to a larger internal magnetic flux area and path length as shown in Figure 12. Expectedly, this solenoidal square coil design can improve the magnetic flux density and eventually enhance the power transfer efficiency and power rating, which however still needs to be tested and proved with actual system output performance and feasibility yet.

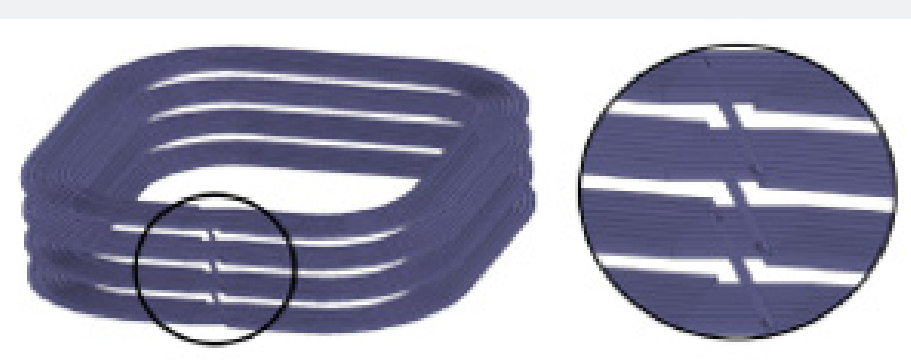

\section{Figure 12. Simulation model of a solenoidal square coil.}

\section{Helical solenoid coils}

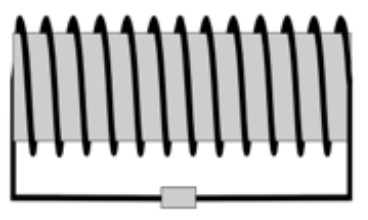

Figure 13. A traditional solenoid coil - side view.

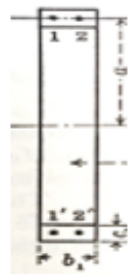

Figure 14. A cross section of single-layered solenoid coil. 
Similar to conventional solenoid structure, the helical solenoid coil categorized here can be one of the applicable CPT coupler designs. As shown in Figures 13\&14 [44], the helical solenoid coil design ideally has two coaxial solenoids with horizontal flux central lines in parallel. With one solenoid as transmitting coil on the primary side and another solenoid as receiving coil on the secondary mounted on the vehicle chassis. Figure 14 shows a cross section of a helical solenoid coil with single-layered windings. This coil structure theoretically has satisfactory mutual inductance when two coils have zero misalignment in parallel and short coupling distance, especially for small electronic devices. However, this design may have low tolerance to misalignments which could be a challenge from the EV customer end in realworld high-power applications if installed on vehicle chassis. Ferrite cores can be inserted into the cylindrical centre in helical solenoid coil design for coupling enhancement.

\section{Multilayer helical coils}

A novel design called 'multi-layered helical coil' is illustrated in Figures15\&16. Theoretically, with numbers of winding turns and layers, the coil coupling, and mutual inductance will be increased, consequently enhancing the CPT system performance. When it comes to high frequency applications like CPT charging for EVs, the total effects of proximity losses will be significant if the distance of each turn and layer separation are too close, which lowers the system efficiency [45]. Thus, this design is not suitable for high frequency, space tightened and high power required applications. Further investigations and experimental results from practical prototypes rather than ideal simulation models are still required to study this multi-layered helical coil design for the feasibility and realization of CPT charging of EVs in the future.

\section{Mixed-type coils design}

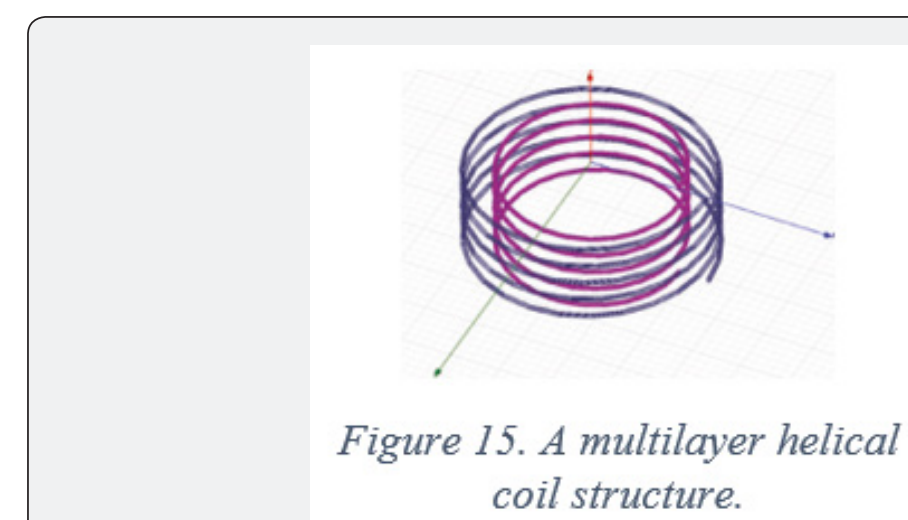

An innovative structure design shown in Figure 17 was proposed by a team in Japan in 2015. This mixed-typed coil design [19] is supposed to allow higher tolerance to misalignments, smaller size and more compact installation for energy receiving side on EVs as two coaxial square solenoid coils on the transmitting side are expected to generate stronger magnetic field in order for the circular receiving coil to capture more amount of magnetic flux lines. Expectedly, the overall coil magnetic flux distribution of the CPT system could be boosted when compared with a pure circular coil design for the same size of chassis of EVs. However, this design still needs to be further theoretically studied, practically tested and comprehensively analysed from modelling to experiment due to few reports in the literature until present.

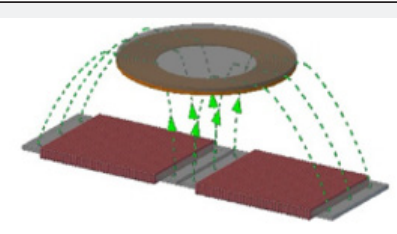

Figure 17. A mixed-type coil design.

\section{Double D coils}

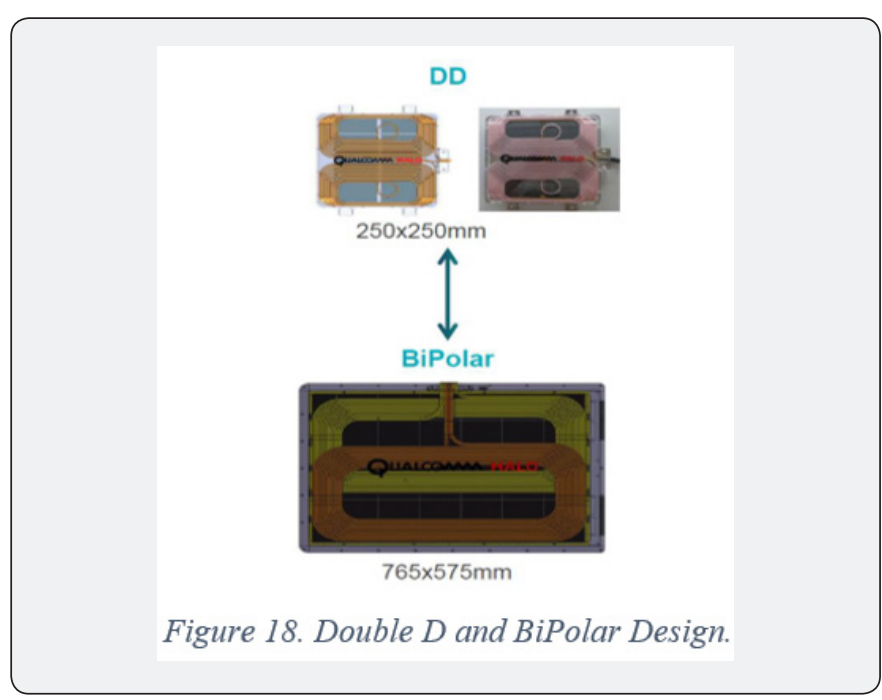

A structure of double D shaped coils was proposed by Qualcomm Halo program as illustrated in Figure 18. Two coils of the ideal D shape winded with one long copper wire are on the 
ground side as a transmitter, and a polarized receiving coil with two partially overlapping windings is on the EV chassis side [46]. This DD design was reported to produce higher coupling than a same-sized circular coil structure $[47,48]$. However, further developments about DD coil design and its derivatives are required by more numerical results and effective system performance.

\section{H-shaped coupler coils}

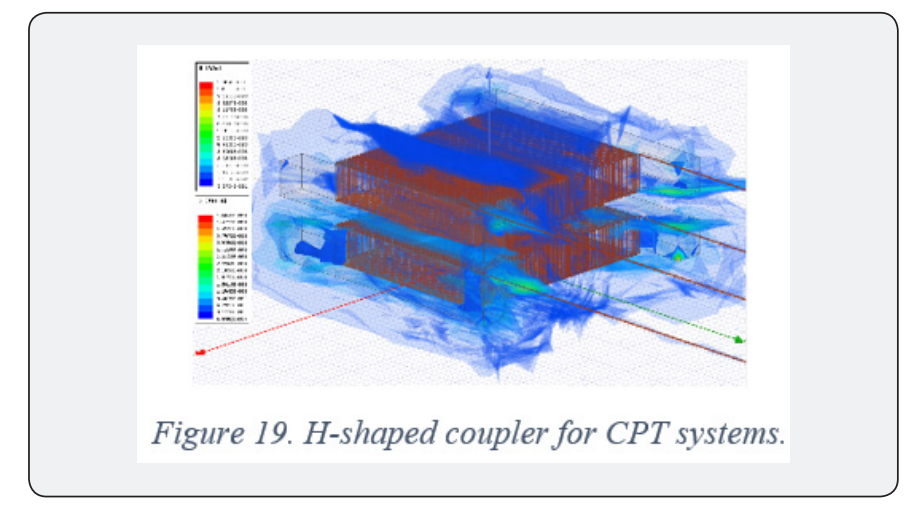

A novel H-shaped coupler with ferromagnetic materials as cores was proposed in $[39,49]$. In order to enhance the magnetic field flux density and CPT coupling performance, different core materials were tested and analysed. Besides, it was found that the objectives of CPT systems can be addressed by adding shielding shells. Especially with aluminium semi-enclosed shielding shell, the CPT prototype can produce better electromagnetic characteristics and output more satisfactory system performance [50], which reflects the effectiveness and feasibility of using ferromagnetic materials and shielding methods Figure 19.

\section{Asymmetric coils}

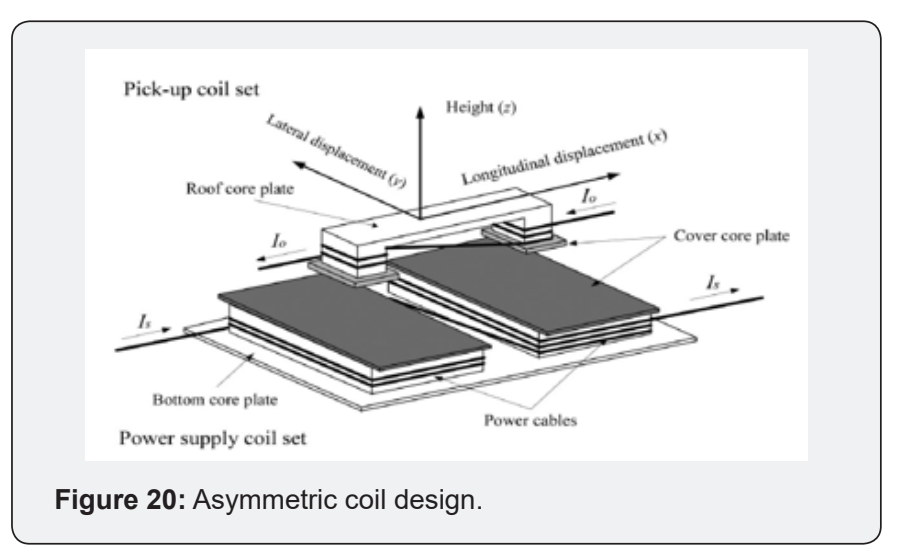

The asymmetric coil structured in Figure 20 was proposed in 2014 in order to investigate the impact of tolerance to the stationary CPT system performance. The receiving coil is smaller than the energy transiting coil set with a purpose of improving the tolerance of misalignments when parking a vehicle [51]. This structurally innovative coupler design with a transmitting bottom set size of $200 \mathrm{~cm} \times 100 \mathrm{~cm}$ each and a pickup set size of $16 \mathrm{~cm} \mathrm{x} 16 \mathrm{~cm}$ each is claimed to output $15 \mathrm{~kW}$ at $20 \mathrm{kHz}$ and the maximum misalignments can be $40 \mathrm{~cm}$ and $20 \mathrm{~cm}$ for lateral and longitudinal axes. This coil design contains ferrite cores as a ferromagnetic material to facilitate the field. The power supply is a current source of maximum $100 \mathrm{~A}$ in the simulation models. Nevertheless, further studies about the feasibility for real-world EVs contactless charging with this type of design are required in the future, addressing the other major objectives of CPT systems.

\section{Conclusion}

In this article, the brief history and basics of CPT systems using inductive power transfer have been introduced. A series of both leading research institutes and pioneer industrial companies worldwide have been listed and discussed in terms of the development directions, proposed methods and concepts over CPT technologies. In addition, most of the currently proposed coupler coil designs have been described and reviewed towards the major objectives of CPT technologies.

\section{References}

1. Chwei-Sen Wang, Covic GA, Stielau OH (2004) Power transfer capability and bifurcation phenomena of loosely coupled inductive power transfer systems. IEEE Trans Ind Electron 51(1): 148-157.

2. Covic GA, Boys JT (2013) Inductive Power Transfer. Proc IEEE 101(6): 1276-1289.

3. Yungtaek Jang, Jovanovic MM (2000) A contactless electrical energy transmission system for portable-telephone battery chargers. INTELEC Twenty-Second International Telecommunications Energy Conference (Cat. No.00CH37131), pp. 726-732.

4. Turner, James B, Roth, Gary W (1990) Regulator for inductively coupled power distribution system. US4914539A.

5. John T Boys, Green AW (1994) Inductive power distribution system. US5293308A.

6. Green AW, Boys JT (1994) $10 \mathrm{kHz}$ inductively coupled power transferconcept and control. in 1994 Fifth International Conference on Power Electronics and Variable-Speed Drives, pp. 694-699.

7. Boys JT, Covic GA, Green AW (2000) Stability and control of inductively coupled power transfer systems. IEE Proc Electr Power Appl 147(1): $37-43$.

8. Onar OC, Miller JM, Campbell SL, Coomer C, Cliff P, et al. (2013) Oak Ridge National Laboratory Wireless Power Transfer Development for Sustainable Campus Initiative. in 2013 IEEE Transportation Electrification Conference and Expo (ITEC), pp. 1-8.

9. Miller JM, White CP, Onar OC, Ryan PM, et al. (2012) Grid side regulation of wireless power charging of plug-in electric vehicles. in 2012 IEEE Energy Conversion Congress and Exposition (ECCE), USA, pp. 261-268.

10. Wu HH, Gilchrist A, Sealy KD, Bronson D (2012) A High Efficiency 5 kW Inductive Charger for EVs Using Dual Side Control. IEEE Trans Ind Inform 8(3): 585-595.

11. Li W (2009) High efficiency wireless power transmission at low frequency using permanent magnet coupling. University of British Columbia, pp. 1-62.

12. Horiuchi T, Kawashima K (2010) Study on Planar Antennas for Wireless Power Transmission of Electric Vehicles. IJTIA 130(12): 1371-1377. 
13. Teck Chuan Beh, Takehiro Imura, Masaki Kato, Yoichi Hori (2010) Basic study of improving efficiency of wireless power transfer via magnetic resonance coupling based on impedance matching. in 2010 IEEE International Symposium on Industrial Electronics, Italy, pp. 20112016.

14. Imura T, Okabe H, Hori Y (2009) Basic experimental study on helical antennas of wireless power transfer for Electric Vehicles by using magnetic resonant couplings. in 2009 IEEE Vehicle Power and Propulsion Conference, pp. 936-940.

15. Imura T, Okabe H, Uchida T, Hori Y (2010) Wireless Power Transfer during Displacement Using Electromagnetic Coupling in Resonance. IEEJ Trans Ind Appl 130(1): 76-83.

16.Zelder T, Geck B (2011) Contactless Scattering Parameter Measurements. IEEE Microw Wirel Compon Lett 21(9): 504-506.

17. Imura T, Y Hori (2011) Maximizing Air Gap and Efficiency of Magnetic Resonant Coupling for Wireless Power Transfer Using Equivalent Circuit and Neumann Formula. IEEE Trans Ind Electron 58(10): 47464752 .

18. Hiramatsu T, Huang X, Kato M, Imura T, Hori Y (2015) Wireless charging power control for HESS through receiver side voltage control. in 2015 IEEE Applied Power Electronics Conference and Exposition (APEC), USA pp. 1614-1619.

19. Imura T, Yasuda T, Oshima K, Nayuki T, Sato M, et al. (2016) Wireless power transfer for electric vehicle at the kilohertz band. IEEJ Trans Electr Electron Eng 11(S2): S91-S99.

20. Imura T, Hori Y (2017) Unified Theory of Electromagnetic Induction and Magnetic Resonant Coupling. Electr. Eng Jpn 199(2): 58-80.

21. Kesler MP (2013) Highly Resonant Wireless Power Transfer: Safe, Efficient, and over Distance. pp: 1-13.

22. Karalis A, Joannopoulos JD, Soljačić M (2008) Efficient wireless nonradiative mid-range energy transfer. Ann Phys 323(1): 34-48.

23. Kurs A, Karalis A, Moffatt R, Joannopoulos JD, Fisher P, et al. (2007) Wireless Power Transfer via Strongly Coupled Magnetic Resonances. Science 317(5834): 83-86.

24. Karalis A, Kurs AB, Moffatt R, Joannopoulos JD, Fisher PH, et al. (2010) Wireless energy transfer. US7825543B2.

25. Wang J, Ho SL, Fu WN, Sun M (2011) Analytical Design Study of a Novel Witricity Charger with Lateral and Angular Misalignments for Efficient Wireless Energy Transmission. IEEE Trans. Magn 47(10): 2616-2619.

26. [2020] Bombardier's PRIMOVE E-buses Pass 500,000 km Milestone. Bombardier Transportation.

27. [2020] HEVO: Wireless Charging for Electric Vehicles.

28. Covic GA (2013) Fact Sheet Series: No. 1-Basic Concepts. Pp: 1-7.

29. Bosshard R, Iruretagoyena U, Kolar JW (2016) Comprehensive Evaluation of Rectangular and Double-D Coil Geometry for $50 \mathrm{~kW} / 85$ kHz IPT System. IEEE J Emerg Sel Top Power Electron 4(4): 406-1415.

30. [2019] Inductive Power Transfer IPT-Charge. Conductix-Wampfler.

31. [2019] Charging electric buses quickly and efficiently: bus stops fitted with modular components make Charge \& Go simple to implementConductix-Wampfler.

32. Laouamer R, Brunello M, Ferrieux JP, Normand O, Buchheit N [1997] A multi-resonant converter for non-contact charging with electromagnetic coupling. in Proceedings of the IECON'97 23rd International Conference on Industrial Electronics, Control, and Instrumentation (Cat. No.97CH36066) 2: 792-797.
33. Sakamoto H, Harada K, Washimiya S, Takehara K, Matsuo Y [1999] Large air-gap coupler for inductive charger [for electric vehicles]. IEEE Trans Magn 35(5): 3526-3528.

34. Hirai J, Tae-Woong Kim, Kawamura A [2000] Study on intelligent battery charging using inductive transmission of power and information. IEEE Trans Power Electron 15(2): 335-345.

35. Liu X, Hui SY (2008) Optimal Design of a Hybrid Winding Structure for Planar Contactless Battery Charging Platform. IEEE Trans Power Electron 23(1): 455-463.

36. Judek S, Karwowski K (2008) Supply of electric vehicles via magnetically coupled air coils. in 2008 13th International Power Electronics and Motion Control Conference pp. 1497-1504.

37. Villa JL, Sallán J, Llombart A, Sanz JF (2009) Design of a high frequency Inductively Coupled Power Transfer system for electric vehicle battery charge. Appl Energy 86(3): 355-363.

38. Duan J, Wang W (2019) Electromagnetic Coupling Optimization by Coil Design Improvements for Contactless Power Transfer of Electric Vehicles. in Proceedings of the Future Technologies Conference (FTC) 2018, pp. 944-958.

39. Duan J, Wang W (2019) Design and analysis of a novel CPT system with soft ferromagnetic material cores and electromagnetic resonant coupling for EVs. Juniper Online J Mater Sci 5(4): 1-12.

40. Shi-Chun Y, Sheng-Zhuang S, Yao-Guang C, Wen-Zhuang G, Fen-zhu J (2014) Research on Efficiency of High Power Resonant Electric Vehicle Contactless Power Transfer Charger. Adv Mech Eng 6: 940890.

41. Onar OC, Miller JM, Campbell SL, Coomer C, Cliff P White (2013) A novel wireless power transfer for in-motion EV/PHEV charging. in 2013 Twenty-Eighth Annual IEEE Applied Power Electronics Conference and Exposition (APEC) pp. 3073-3080.

42. Sallan J, Villa JL, Llombart A, Sanz JF (2009) Optimal Design of ICPT Systems Applied to Electric Vehicle Battery Charge. IEEE Trans Ind Electron 56(6): 2140-2149.

43. Wang J, Hu M, Cai C, Lin Z, Li L, et al. (2018) Optimization design of wireless charging system for autonomous robots based on magnetic resonance coupling. AIP Adv 8(5): 055004.

44. Grover FW (1962) Inductance Calculations: Working Formulas and Tables. Dover.

45. Vilathgamuwa DM, Sampath JPK (2015) Wireless Power Transfer (WPT) for Electric Vehicles (EVs)-Present and Future Trends. In: Rajakaruna S, Shahnia F, Ghosh A, (eds.), in Plug in Electric Vehicles in Smart Grids. Springer Singapore, Singapore, pp. 33-60.

46. Budhia M, Boys JT, Covic GA, Huang CY (2013) Development of a SingleSided Flux Magnetic Coupler for Electric Vehicle IPT Charging Systems. IEEE Trans Ind Electron 60(1): 318-328.

47. Boys JT, Covic GA (2015) The Inductive Power Transfer Story at the University of Auckland. IEEE Circuits Syst Mag 15(2): 6-27.

48. Zaheer A, Hao H, Covic GA, Kacprzak D (2015) Investigation of Multiple Decoupled Coil Primary Pad Topologies in Lumped IPT Systems for Interoperable Electric Vehicle Charging. IEEE Trans Power Electron 30(4): 1937-1955.

49. Duan J, Wang W (2020) An Optimal Design of Contactless Power Transfer System Applied for Electric Vehicles Using Electromagnetic Resonant Coupling. in Proceedings of the Future Technologies Conference (FTC), pp. 919-933.

50. Duan J, Wang W (2019) A Novel Coupler Design and Analysis with Shielding Material Tests for a CPT System of Electric Vehicles Based on 
Electromagnetic Resonant Coupling. IOP Conf Ser Mater Sci Eng 647: 1-17.

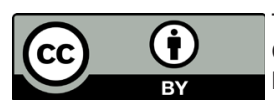

This work is licensed under Creative Commons Attribution 4.0 License

DOI: 10.19080/JOJMS.2020.05.555675
51. Choi SY, Huh J, Lee WY, Rim CT (2014) Asymmetric Coil Sets for Wireless Stationary EV Chargers with Large Lateral Tolerance by Dominant Field Analysis. IEEE Trans Power Electron 29(12): 6406-6420.

\section{Your next submission with Juniper Publishers will reach you the below assets}

- Quality Editorial service

- Swift Peer Review

- Reprints availability

- E-prints Service

- Manuscript Podcast for convenient understanding

- Global attainment for your research

- Manuscript accessibility in different formats

( Pdf, E-pub, Full Text, Audio)

- Unceasing customer service

Track the below URL for one-step submission https://juniperpublishers.com/online-submission.php 